\title{
Effect of Solid Solution Temperature on Microstructure and Corrosion Resistance of CoNiCrMo Alloy
}

\author{
Ya-jie Chu ${ }^{a, b *}$, Ben-xing Hao ${ }^{a}$, Peng Liu ${ }^{c}$, Yuan-bin Zhang \\ ${ }^{a}$ Department of Material Science and Engineering, Nanjing Institute of Technology, \\ Nanjing 211167, P. R. China \\ ${ }^{b}$ Jiangsu Key Laboratory of Advanced Structural Materials and Application Technology, \\ Nanjing 211167, P. R. China \\ ${ }^{c}$ School of Materials Science and Engineering, Shandong Jianzhu University, Jinan 250101, P. R. .China
}

Received: January 24, 2019; Revised: August 24, 2019; Accepted: August 27, 2019

Influence of solid solution temperature on microstructures and corrosion properties of $\mathrm{CoNiCrMo}$ alloy were investigated by means of optical microscopy (OM), scanning electron microscope (SEM) and electronic differential system. The corrosion resistance of CoNiCrMo alloy in $0.9 \% \mathrm{NaCl}$ aqueous solution was also investigated. The results indicated that with the increase of solution treatment temperature, the dendrites of CoNiCrMo alloy gradually disappeared. Thus, the corrosion resistance of the alloy decreased. When the solution temperature is $1200^{\circ} \mathrm{C}$, the dendrites almost disappeared and most carbide dissolved, and begins to spheroidization. The corrosion resistance of CoNiCrMo alloy treated at $1000^{\circ} \mathrm{C}$ for $1 \mathrm{~h}$ is the highest than the one at $1100^{\circ} \mathrm{C}$ and $1200^{\circ} \mathrm{C}$. Its self-corrosion potential is $-424 \mathrm{mV}$ and self-corrosion current density is $1.02 \times 10^{-8} \mathrm{~A} / \mathrm{cm}^{2}$.

Keywords: Co-based alloys; heat treatment; corrosion resistance; microstructure.

\section{Introduction}

Co-based alloys that have excellent comprehensive properties, such as high temperature fatigue resistance, low thermal expansion coefficient, heat corrosion resistance and wear resistance, good biocompatibility, high mechanical properties and high thermal conductivity, were widely used in the fields of military, chemical industry, energy and Bioengineering ${ }^{1-3}$.

At present, the researches on biomedical metal materials have become a hot spot in the global material industry ${ }^{4-6}$. It is well known that Co-based alloys have been widely used in various medical implants to replace and repair the body bones, damaged joints, dental decay, mutant necrotic tissues and organs ${ }^{7,8}$. Moreover, Co-based alloy has stronger corrosion resistance and the similar biocompatibility compared with stainless steel, and the abrasive resistance of Co-based alloys is the best among all biomedical metal materials. Co-based alloys are more suitable for long-term implant under poor load conditions ${ }^{9,10}$. Some studies ${ }^{10-13}$ indicated that Co-based alloys are very sensitive to heat treatment process, and different treatment temperature and holding time during the solution and aging will greatly affect the microstructures, mechanical properties and corrosion resistance of this alloy. For example, Laser cladding Cobased-VN alloy-Ti composite coatings was aging treated at $550{ }^{\circ} \mathrm{C}, 650{ }^{\circ} \mathrm{C}$ and $750{ }^{\circ} \mathrm{C}$, respectively. It was found that the intensities of $\mathrm{Cr}_{23} \mathrm{C}_{6}$, TiN and $\mathrm{VC}$ diffraction peaks were gradually improved as aging temperature increased.The

*e-mail: chuyajie@njit.edu.cn microhardness and wear resistance of Co-based-VN alloy-Ti composite coatings were firstly reduced and then increased as aging temperature increased, the microhardness was increased by $7.9 \%$, and the wear loss was reduced by $8.4 \%$, for aging treatment at $750^{\circ} \mathrm{C}$. The microstructure and tensile properties of Co-27Cr-6Mo (mass\%) alloys heat-treated at 673-1373 K were studied. When low-temperature heat treatment (LTHT) was applied at $673-873 \mathrm{~K}$, both the ultimate tensile strength and elongation synchronously improved compared with the solution-treated alloy.

According to above references, Co-based alloys have excellent comprehensive properties used in biomedical field. When $\mathrm{Ni}$ is added to co-based alloys, this alloy will have high toughness and elasticity. Therefore, the CoNiCrMo alloy will be studied in this paper. However, now, it is lack of no systematic report on the effect of different heat treatment conditions on the microstructures and corrosion properties of CoNiCrMo alloy. Therefore, it is quite necessary to know the relation between heat treatment process and microstructural properties for Co-based alloys.

In this paper, the effect of solid solution temperature on the microstructures and corrosion properties of $\mathrm{CoNiCrMo}$ alloy will be deeply studied, and the mechanism of heat treatment process on the corrosion resistance of $\mathrm{CoNiCrMo}$ alloy will be clarified.

\section{Experimental Techniques}

In this experiment, CoNiCrMo alloy was melted in high purity argon atmosphere by medium frequency induction 
furnace. Then cast to remove the outer surface of the nonuniform composition, and obtain CoNiCrMo alloy ingot of uniform composition. The chemical composition of this alloy is shown in Table 1. And then, a series of samples were cut into $\Phi 9 \mathrm{~mm} \times 19 \mathrm{~mm}$ cylinders by lining cutting machine. Some samples were firstly treated by solid solution at $1000^{\circ} \mathrm{C}$, $1100^{\circ} \mathrm{C}$ and $1200^{\circ} \mathrm{C}$, and then these samples were treated by water cooling after holding for $1 \mathrm{~h}$. All above samples treated will be polished and polished. The microstructure of the alloy was observed by means of metallographic microscope, and a solution that consisted of $\mathrm{HCl}: \mathrm{HNO}_{3}=3: 1$ was used. The surface morphology and element distribution of the samples were observed by JSM-6380LV scanning electron microscopy (SEM) and energy dispersive spectrometer (EDS).

Potentiodynamic polarization curves and electrochemical impedance spectroscopy (EIS) of the alloy were measured using Princeton Electrochemical Workstation Three-electrode system (PEWT). The working electrode was the sample to be tested, and the reference electrode was the saturated calomel electrode. Moreover, the auxiliary electrode was the platinum electrode, and the corrosion medium was in $0.9 \% \mathrm{NaCl}$ solution. The temperature was maintained at $37 \pm 0.5^{\circ} \mathrm{C}$. The test area of the sample is $1 \mathrm{~cm}^{2}$. Before testing, the sample was placed in the $0.9 \% \mathrm{NaCl}$ solution for $1 \mathrm{~h}$ to stabilize. The potentiodynamic scanning rate is $0.5 \mathrm{mV} / \mathrm{s}$ and the scanning range was from $-1 \mathrm{~V}$ to $1 \mathrm{~V}$. The frequency range of electrochemical impedance (EIS) measurement is from $10 \mathrm{mHz}$ to $100 \mathrm{kHz}$, and the amplitude of excitation voltage is $10 \mathrm{mV}$. The spectrum is analyzed by Zsimpwin software.

\section{Results and Analysis}

\subsection{Microstructures}

As Co and Ni can form infinite solid solution and Ni is an austenite stabilizing element. Therefore, the CoNiCrMo alloy with higher Ni content should be austenite structure. Fig. 1 shows the metallographic photograph of CoNiCrMo alloy after solution treatment at different temperatures. It can be seen from the graph that with the increase of solution temperature, the dendrites of Co-based alloy gradually disappeared and melted into the matrix. Meanwhile, the interdendritic precipitates also decreased. When the temperature rose to $1200^{\circ} \mathrm{C}$, the dendrites almost disappeared and most carbide dissolved, and begins to spheroidization.

Figs. 2-4 are the SEM and EDS results of CoNiCrMo alloy after solution treatment at $1000^{\circ} \mathrm{C}, 1100^{\circ} \mathrm{C}$ and $1200^{\circ} \mathrm{C}$. As can be seen from the graph, the deeper color of the dendrites branches indicates that they are corroded, while the lighter color of the parts between the dendrites branches indicates that they are more resistant to corrosion. EDS analysis indicated that the dendrites branches were mainly composed of Co elements, thus the content of Co elements was significantly higher than that of the inter-branches of dendrites, while the inter-branches of dendrites were composed of corrosionresistant elements. As shown in Fig. 2, the content of Co at $\mathrm{B}$ area is $27.40 \%$, much higher than that at $\mathrm{A}$ area $(11.99 \%)$. With the increase of solution temperature, the corrosion resistant elements between dendrites branches gradually dissolve into the matrix, but the residual content of $\mathrm{Cr}$ among dendrites branches is still very high. Further observation by EDS showed that the particulate matter contained higher $\mathrm{Cr}$ element, and there were obvious corrosion pits around the particulate matter, which were more evident at $1100^{\circ} \mathrm{C}$ and $1200^{\circ} \mathrm{C}$ (see Fig. 3 and Fig. 4). Some studies indicated that carbides in Co-based alloys often occurred in the form of $\mathrm{M}_{23} \mathrm{C}_{6}(\mathrm{M}=\mathrm{Co}, \mathrm{Cr}, \mathrm{Mo}){ }^{14-16}$. In this experiment, it was found that the content of $\mathrm{Cr}$ in carbides reached to $63.33 \%$ (point A in Fig. 4). Corrosion pits mostly occur around carbides, and the local corrosion performance is greatly reduced due to the presence of carbides.

\subsection{Corrosion resistance analysis}

In order to compare the corrosion resistance of CoNiCrMo alloy in saline solution under different heat treatment conditions, the dynamic polarization curves and electrochemical impedance experiments were carried out respectively. Normally, the self-corrosive potential (Ecorr) in the polarization curve is a thermodynamic parameter to evaluate the corrosion resistance of alloys. The self-corrosive potential reflects the degree of corrosion difficulty of alloys. With the increase of self-corrosion potential, the corrosion of the alloys is more difficult. Corrosion current and polarization resistance are the dynamic parameters reflecting the corrosion resistance of alloys. Higher corrosion current indicates that once the material is corroded, the corrosion speed will be accelerated. Corrosion current reflects the corrosion degree and corrosion rate of alloys ${ }^{17,18}$.

Fig. $5 \mathrm{a}$ is the dynamic polarization curve of $\mathrm{CoNiCrMo}$ alloy after different solution temperatures. The polarization curves of different treatment processes are approximately the same. Tafel linear fitting analysis of the polarization curves can obtain the relevant electrochemical parameters, as shown in Table 2.

From the fitting values in Table 2, it can be seen that the corrosion current densities of CoNiCrMo alloys treated by solid solution in saline water are relatively low. Among them, the corrosion current density is the smallest and the corrosion potential is positive after $1000^{\circ} \mathrm{C}$ solid solution treatment. It can be seen from Fig. 5a that with the increase

Table 1. The Chemical composition of CoNiCrMo alloy (wt.\%).

\begin{tabular}{lccccccc}
\hline Co & $\mathrm{Ni}$ & $\mathrm{Cr}$ & $\mathrm{Mo}$ & $\mathrm{Fe}$ & $\mathrm{S}$ & \\
\hline 27.40 & 30.50 & 22.97 & 5.44 & 11.79 & 1.75 & 0.15 & \\
\hline
\end{tabular}




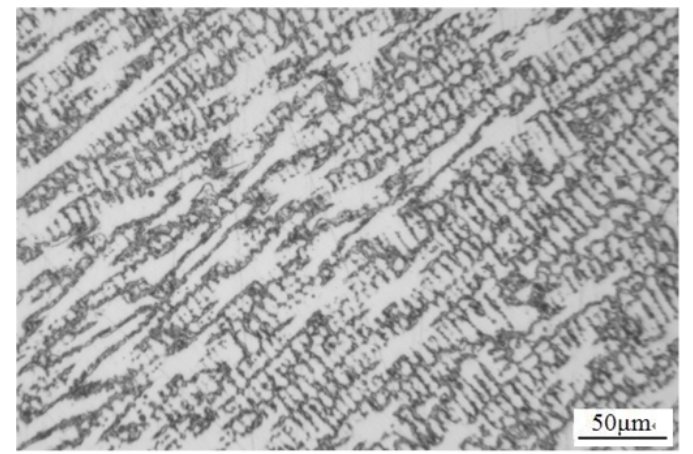

(a) $1000^{\circ} \mathrm{C}$

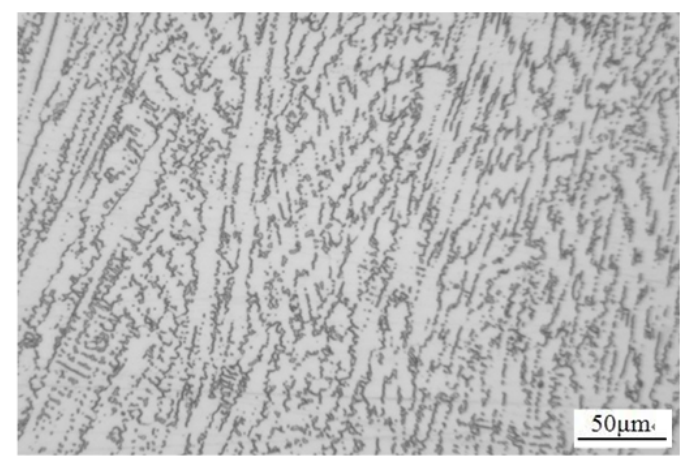

(b) $1100^{\circ} \mathrm{C}$

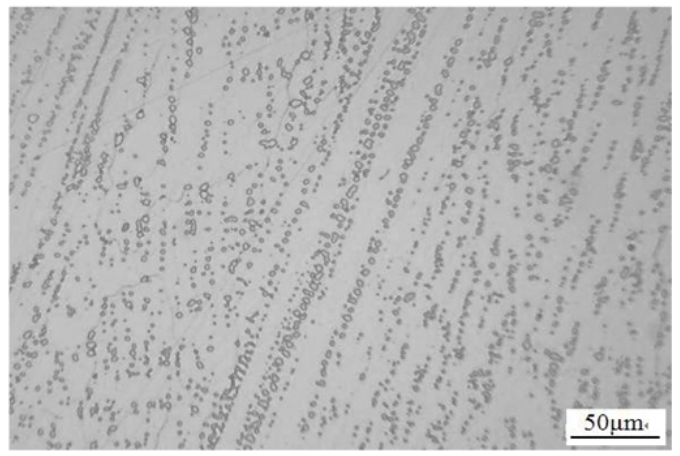

(c) $1200^{\circ} \mathrm{C}$

Figure 1. Microstructure of CoNiCrMo alloy at different solution temperatures for $1 \mathrm{~h}$ (a) $1000^{\circ} \mathrm{C}$; (b) $1100^{\circ} \mathrm{C}$; (c) $1200^{\circ} \mathrm{C}$

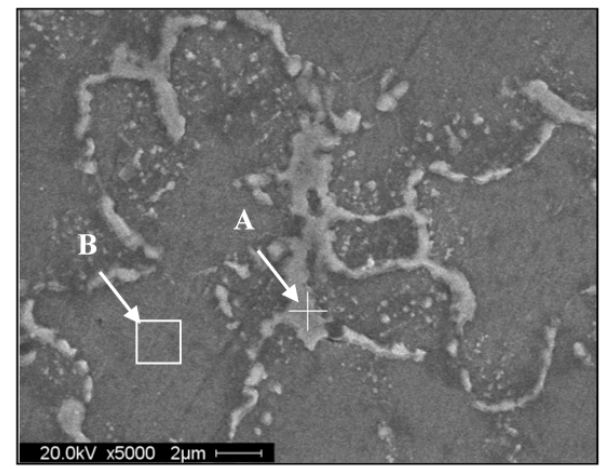

(a) $\mathrm{SEM}$ at $1000^{\circ} \mathrm{C}$

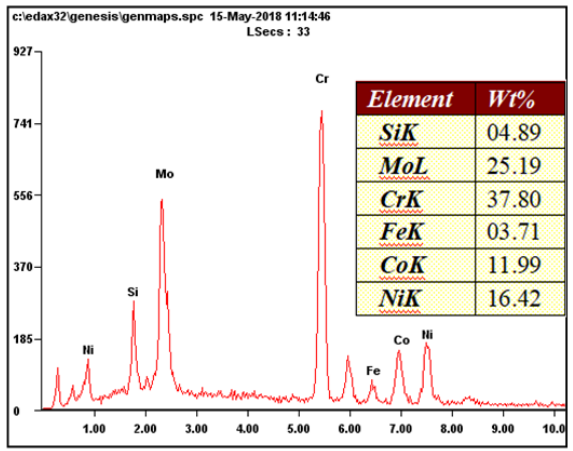

(b) EDS of point A

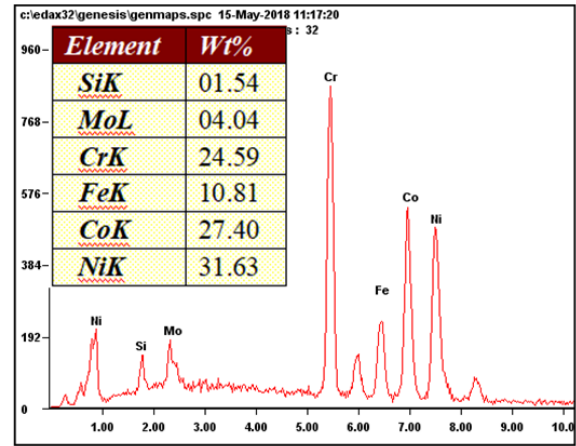

(c) EDS of point $\mathrm{B}$

Figure 2. SEM and EDS of CoNiCrMo alloy for $1 \mathrm{~h}$ at $1000^{\circ} \mathrm{C}$ solid solution treatment. 


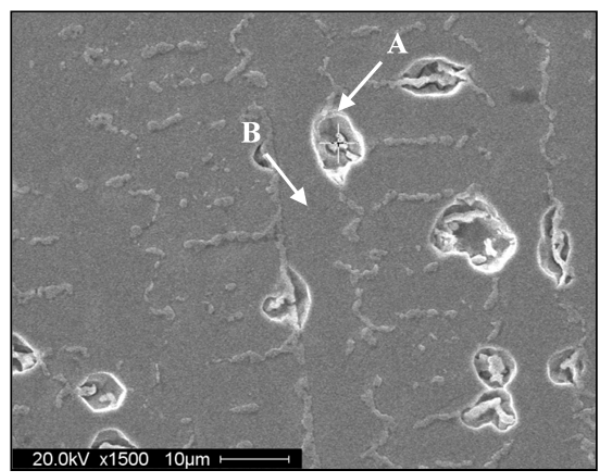

(a) SEM at $1100^{\circ} \mathrm{C}$

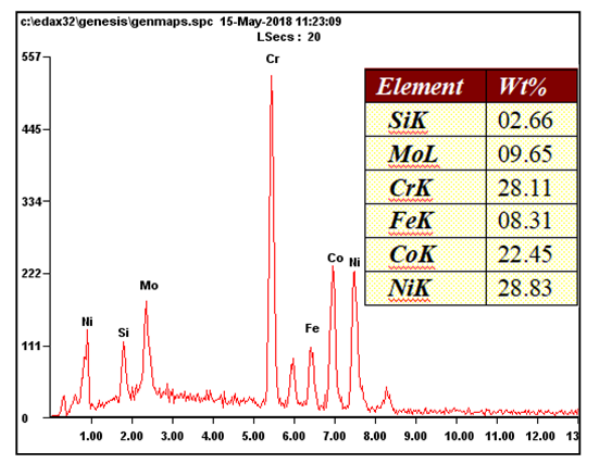

(b) EDS of point $\mathrm{A}$

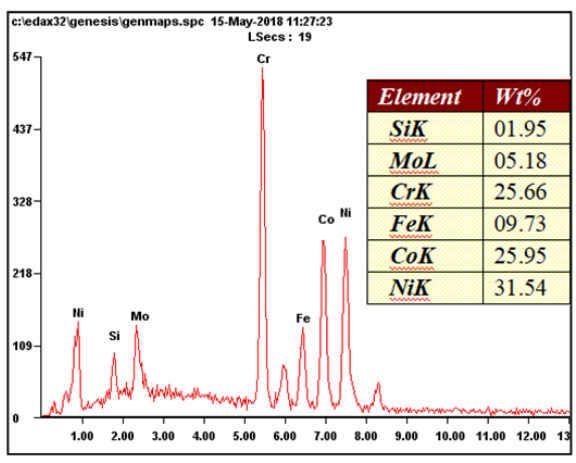

(c) EDS of point $\mathrm{B}$

Figure 3. SEM and EDS of CoNiCrMo alloy for $1 \mathrm{~h}$ at $1100^{\circ} \mathrm{C}$ solid solution treatment.

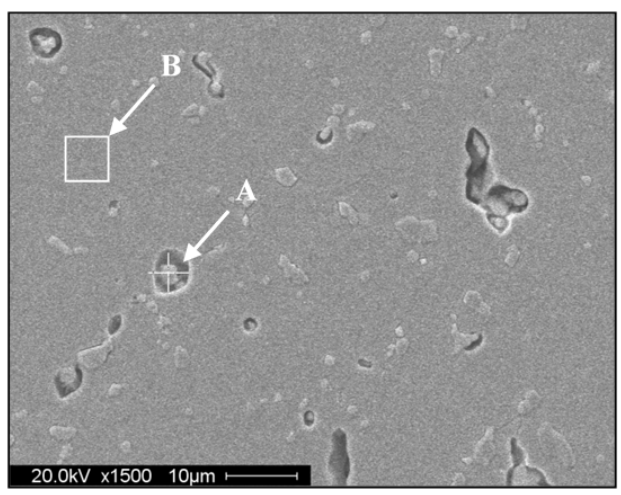

(a) SEM at $1200^{\circ} \mathrm{C}$

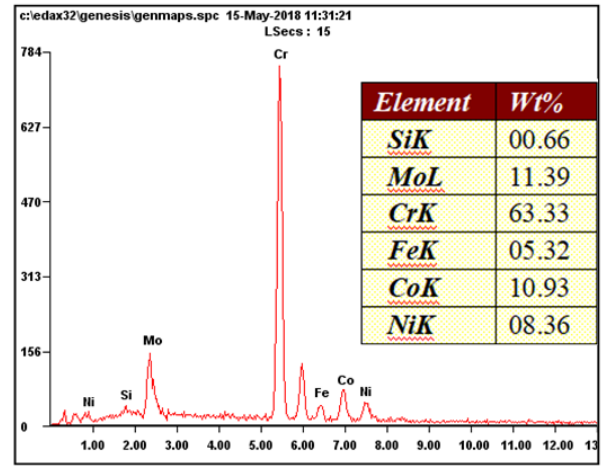

(b) EDS of point $\mathrm{A}$

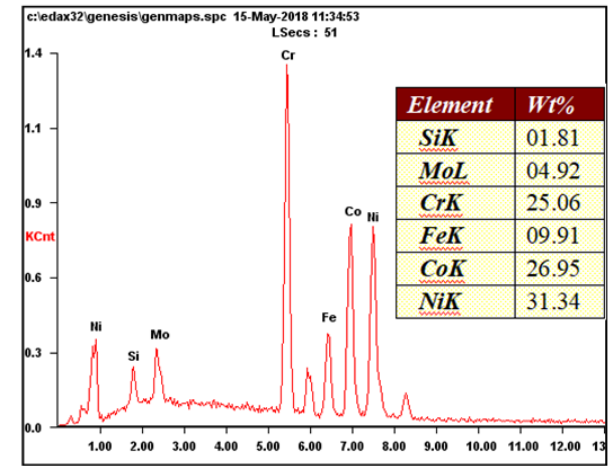

(c) EDS of point $\mathrm{B}$

Figure 4. SEM and EDS of CoNiCrMo alloy for $1 \mathrm{~h}$ at $1200^{\circ} \mathrm{C}$ solid solution treatment. 


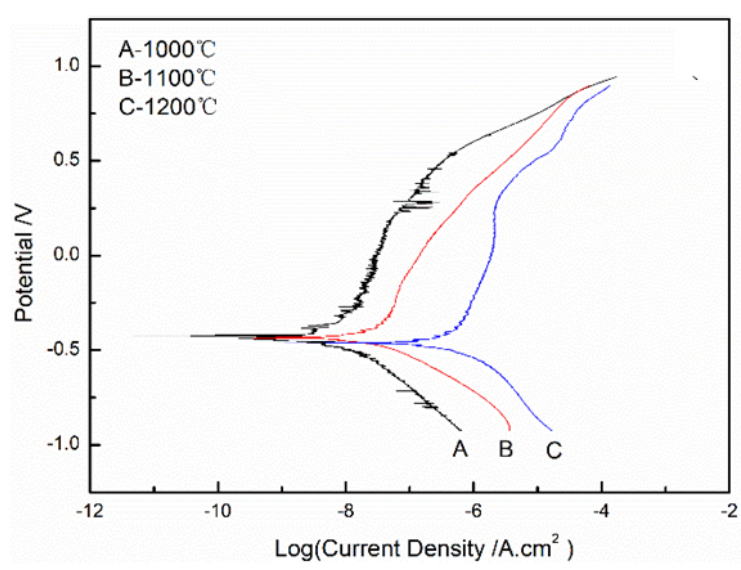

(a) Polarization curves

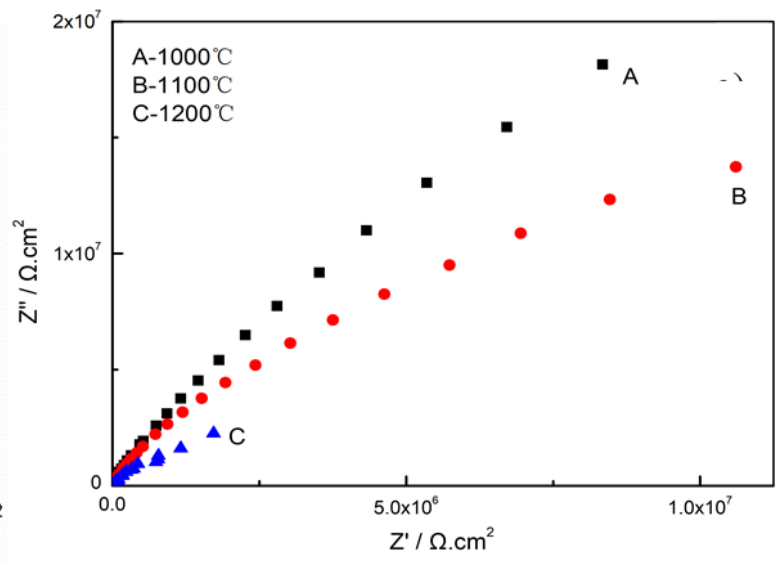

(b) EIS curves

Figure 5. Polarization and EIS curves of CoNiCrMo alloy at different solution temperature.

Table 2. Corrosion resistance parameters of CoNiCrMo alloy.

\begin{tabular}{lccccc}
\hline Temperature & $E_{\text {corr }} / \mathrm{mV}$ & $I_{\text {corr }} /\left(\mathrm{A} \cdot \mathrm{cm}^{-2}\right)$ & $R_{\mathrm{p}} /\left(\mathrm{k} \Omega \cdot \mathrm{cm}^{-2}\right)$ & $\beta_{\mathrm{a}} / \mathrm{V} \cdot \mathrm{dec}^{-1}$ & $\beta_{\mathrm{c}} / \mathrm{V} \cdot \mathrm{dec}^{-1}$ \\
\hline $1000^{\circ} \mathrm{C}$ & -424 & $1.02 \times 10-8$ & 16700 & 0.926 & -0.276 \\
$1100^{\circ} \mathrm{C}$ & -436 & $3.72 \times 10-8$ & 4900 & 0.649 & -0.256 \\
$1200^{\circ} \mathrm{C}$ & -461 & $47.9 \times 10-8$ & 474 & 0.693 & -0.298 \\
\hline
\end{tabular}

of solution treatment temperature the corrosion potential of CoNiCrMo alloy becomes more and more negative, and the corrosion current becomes larger and larger. From the point of view of polarization resistance, the value of polarization resistance decreases sharply with the increase of solution treatment temperature. With the increase of the polarization resistance, the corrosion resistance of the alloy is also improved further. With the increase of solution temperature, the polarization curve shifts to the right and downward gradually. This indicates that the corrosion potential is more negative, the corrosion current density is higher, and the corrosion resistance is worse. Therefore, the comprehensive analysis of self-corrosion current, selfcorrosion potential and polarization resistance shows that the corrosion resistance of CoNiCrMo alloy after $1 \mathrm{~h}$ solid solution treatment at $1000^{\circ} \mathrm{C}$ is the best.

The corrosion resistance of CoNiCrMo alloy treated at $1000^{\circ} \mathrm{C}$ for $1 \mathrm{~h}$ is the best. Its self-corrosion potential is $-424 \mathrm{mV}$, self-corrosion current density is $1.02 \times 10^{-8} \mathrm{~A} / \mathrm{cm}^{2}$, polarization resistance is $16700 \mathrm{k} \Omega / \mathrm{cm}^{2}$, anode slope is $0.926 \mathrm{~V} / \mathrm{dec}$ and cathode slope is $-0.276 \mathrm{~V} / \mathrm{dec}$. The results are according to above microstructural analysis. With the increase of solution temperature, the poor $\mathrm{Cr}$ phenomenon and serious pitting corrosion occur around carbides in $\mathrm{CoNiCrMo}$ alloy after solution treatment at different temperatures. In addition, it can be seen that the breakdown potential $\left(\mathrm{E}_{\mathrm{b}}\right)$ of each sample will occur corrosive pitting rapidly when the applied potential is greater than the breakdown potential
$\left(\mathrm{E}_{\mathrm{b}}\right)$. The breakdown potential of CoNiCrMo alloy after solution treatment at $1000^{\circ} \mathrm{C}$ is the highest, $480 \mathrm{mV}$. This indicates that its resistance to pitting corrosion is the best, while that of CoNiCrMo alloy after solution treatment at $1200^{\circ} \mathrm{C}$ is the lowest and its resistance to pitting corrosion is poor, which basically coincides with the analysis of scanning electron microscopy.

Fig. $5 \mathrm{~b}$ shows the electrochemical impedance spectra of CoNiCrMo alloy under different solution temperature. The $\mathrm{X}$-axis is the real part of impedance and the Y-axis is the imaginary part of impedance. It can be seen that there is only one capacitive impedance arc arc in the impedance test of CoNiCrMo alloy in saline solution different solution temperatures. The radius of capacitive impedance arc reflects the resistance value during charge transfer. The larger the radius of capacitance impedance arc, the larger the electron transfer resistance and the worse the conductivity, and the better the corrosion resistance of the alloys ${ }^{19,20}$. The radius of capacitive impedance arc of the alloy treated at $1000^{\circ} \mathrm{C}$ is obviously larger than that of the other two temperatures, which indicates that the corrosion resistance of the CoNiCrMo alloy treated at this temperature is obviously better than that of the other two solid solution treatment temperatures.

\section{Conclusions}

(1) The dendrites of CoNiCrMo alloy gradually disappeared and melted into the matrix with the increase of solution 
temperature. Meanwhile, the interdendritic precipitates also decreased. When the solution temperature is $1200^{\circ} \mathrm{C}$, the dendrites almost disappeared and most carbide dissolved, and begins to spheroidization. However, the residual content of $\mathrm{Cr}$ among dendrites branches is still high. Corrosion pits mostly occur around carbides, and the local corrosion performance is greatly reduced due to the presence of carbides.

(2) With the increase of solution treatment temperature the corrosion potential of CoNiCrMo alloy becomes more and more negative. The corrosion resistance of CoNiCrMo alloy after $1 \mathrm{~h}$ solid solution treatment at $1000^{\circ} \mathrm{C}$ is the best. Its self-corrosion potential is $-424 \mathrm{mV}$ and self-corrosion current density is $1.02 \times 10^{-8} \mathrm{~A} / \mathrm{cm}^{2}$. The electrochemical impedance spectra (ESI) also indicated that the corrosion resistance of the CoNiCrMo alloy treated at this temperature is obviously better than that of the other two solid solution treatment temperatures.

\section{Acknowledgement}

This research is financially supported by the National Natural Science Foundation of China (61703200), the Innovation Foundation of Nanjing Institute of Technology (CKJA201404), the Opening Project of Jiangsu Key Laboratory of Advanced Structural Materials and Application Technology (ASMA201610) and the Shandong Provincial Natural Science Foundation, China (Grant No. ZR2016JL017).

\section{References}

1. Cartón-Cordero M, Campos M, Freund LP, Kolb M, Neumeier S, Göken M, Torralba JM. Microstructure and compression strength of Co-based superalloys hardened by gamma' and carbide precipitation. Materials Science and Engineering: $A$. 2018;734:437-444.

2. Cosimati R, Mari D. Hysteretic Behavior of Twin Boundary Peak Due to Precipitation in Co-Ni-Cr alloy. Materials Research. 2018;21(Suppl 2):e20170896.

3. Freund LP, Stark A, Pyczak F, Schell N, Göken M, Neumeier $\mathrm{S}$. The grain boundary pinning effect of the mu phase in an advanced polycrystalline gamma/gamma' Co-base superalloy. Journal of Alloys and Compounds. 2018;753:333-342.

4. Wang Z, Yan Y, Xing L, Su Y, Qiao L. The role of hard phase carbides in tribocorrosion processes for a Co-based biomedical alloy. Tribology International. 2017;113:370-376.

5. Zhou Z, Wei Q, Li Q, Jiang B, Chen Y, Sun Y. Development of Co-based bulk metallic glasses as potential biomaterials. Materials Science and Engineering: C. 2016;69:46-51.

6. Zhang E, Liu C. A new antibacterial Co-Cr-Mo-Cu alloy: Preparation, biocorrosion, mechanical and antibacterial property. Materials Science and Engineering: C. 2016;69:134-143.

7. Dehaghani MT, Ahmadian M. Porous vitalium-base nano-composite for bone replacement: Fabrication, mechanical, and in vitro biological properties. Journal of the Mechanical Behavior of Biomedical Materials. 2016;57:297-309.
8. Santecchia E, Gatto A, Bassoli E, Denti L, Rutkowski B, Mengucci P, Barucca G. Precipitates formation and evolution in a Cobased alloy produced by powder bed fusion. Journal of Alloys and Compounds. 2019;797:652-658.

9. Choroszynski M, Choroszynski MR, Skrzypek SJ. Biomaterials for hip implants - important considerations relating to the choice of materials. Bio-Algorithms and Med-Systems. 2017;13:133-145.

10. Jovanovic M. Nikel, Cobalt and Titanium-based alloys-from aircraft vehicles to medical applications. Metallurgical Materials Engineering. 2016;22(3):205-220.

11. Elmanov GN, Chernavskii PA, Kozlov IV, Dzhumaev PS, Kostitsyna EV, Tarasov VP, Ignatov AS, Gudoshnikov SA. Effect of heat treatment on phase transformations and magnetization of amorphous $\mathrm{Co}_{69} \mathrm{Fe}_{4} \mathrm{Cr}_{4} \mathrm{Si}_{12} \mathrm{~B}_{11}$ microwires. Journal of Alloys and Compounds. 2018;741:648-655.

12. Ding L, Hu SS, Quan X, Shen JQ. Microstructure evolution and tribological properties of Co-based-VN alloy-Ti composite coatings by aging treatment. Surface and Coatings Technology. 2017;330:178-184.

13. Ueki K, Abe M, Ueda K, Nakai M, Nakano T, Narushima T. Synchronous improvement in strength and ductility of biomedical Co-Cr-Mo alloys by unique low-temperature heat treatment. Materials Science and Engineering: A. 2018;739:53-61.

14. Hassani FZ, Ketabchi M, Ebrahimi GR, Bruschi S. Hot compression deformation characteristics and microstructural evolution of a $\mathrm{Co}-\mathrm{Cr}-\mathrm{Mo}-\mathrm{C}$ alloy: Effect of precipitate and martensitic transformation. Materials Science and Engineering: A. 2016;657:383-392

15. Jing QF, Tan YF. Microstructure and Tribological Properties of Cobalt-based Stellite 6 Alloy Coating by Electro-Spark Deposition. Materials Research. 2013;16(5):1071-1076.

16. Hassani FZ, Ketabchi M, Ebrahimi GR, Bruschi S. Hot compression deformation characteristics and microstructural evolution of a Co-Cr-Mo-C alloy: Effect of precipitate and martensitic transformation. Materials Science and Engineering: A. 2016;657:383-92. Available from: <https://www.sciencedirect. com/journal/materials-science-and-engineering-a/vol/657/suppl/C>

17. Lu Y, Guo S, Yang Y, Liu Y, Zou Y, Wu S, Zhao C, Lin J. Effect of thermal treatment and fluoride ions on the electrochemical corrosion behavior of selective laser melted CoCrW alloy. Journal of Alloys and Compounds. 2018;730:552-562.

18. Kolb M, Freund LP, Fischer F, Povstugar I, Makineni SK, Gault B, Raabe D, Muller J, Spiecker E, Neumeier S, Göken M. On the grain boundary strengthening effect of boron in gamma/gamma' Cobalt-base superalloys. Acta Materialia. 2018;145:247-254.

19. Gao X, Xia C, Zhang X, Jing Q, Ma M, Qin J, Liu R. Effects of iron content on the microstructure and corrosion behavior of Ti-30Zr-5Al-3V-xFe alloys. Materials Chemistry and Physics. 2018;218:87-97.

20. Liu C, Zhou Z, Li KY. Improved corrosion resistance of CoCrMo alloy with self-passivation ability facilitated by carbon ion implantation. Electrochimica Acta. 2017;241:331-340. 